\title{
Editorial Otoño 2017
}

El contexto político, económico, social y, consecuentemente, el universo jurídico en nuestro país; nos interpela al lanzamiento de este nuevo número de ReDeA con estupor. Pero, lejos de ser paralizante, nos incentiva a profundizar nuestro pensamiento crítico y traducirlo en propuestas revitalizantes y superadoras.

El primer escaño de la lista de sucesos alarmantes queda reservado, sin duda, al fallo de la Corte Suprema de Justicia de la Nación, recientemente conformada, que habilitó la aplicación del beneficio excepcional previsto por la ley 24.390 conocido como " 2 x 1" en el cómputo de condenas a genocidas que fueron juzgados por los delitos más atroces de nuestra historia reciente. Dejando así abierta la posibilidad de que los represores condenados por delitos de lesa humanidad queden en libertad. Esta sentencia, dictada en una situación procesal particular abstracta y, por ello, más simbólica que de consecuencias jurídicas efectivas en el caso concreto; provocó la reacción de los Organismos de Derechos Humanos, así como de toda la sociedad argentina que tiene en su ADN el legado de Memoria, Verdad y Justicia. Adherimos al reclamo por su no aplicación, haciendo nuestros los conceptos de Estela de Carlotto -titular de Abuelas de Plaza de Mayo-, quien sostuvo que: "Estos delitos no concluyen hasta que no se sepa el destino de los desaparecidos y de los nietos apropiados. Lo que no se juzga y se condena, se repite".

Por otra parte; advertimos con profunda preocupación y rechazo, la injerencia que el Poder Ejecutivo Nacional está ejerciendo sobre el Poder Judicial en todos sus niveles de competencia.

Meses atrás, se designó como Juez subrogante en el Juzgado Federal 1 de La Plata a un juez federal, de otra jurisdicción, en una clara maniobra tendiente a contar con un juez cercano, para que quede a cargo, ni más ni menos, del próximo proceso electoral en la Provincia de Buenos Aires.

En la misma línea; un juez de la Cámara Nacional de Casación Criminal y Correccional, que recientemente había sido Ministro de Justicia del Poder Ejecutivo de la Provincia de Buenos Aires, fue trasladado hacia la Cámara Federal de Casación Penal. Ambos casos fueron cuestionados judicialmente por las irregularidades en el proceso de selección de estos jueces para ocupar los roles asignados, sustanciadas por el Consejo de la Magistratura. No obstante, a pesar de seguir tramitando las acciones judiciales, la propia Justicia Federal no ha sido determinante a la hora de impedir preventivamente las asunciones de los cargos cuestionados.

Tercer escaño: días pasados se resolvió judicialmente la remoción de un senador como Consejero de la Magistratura por no tener título de abogado, mediante la declaración de inconstitucionalidad de un artículo de la ley aplicable 26.855. Ley que se encuentra vigente desde hace cua- tro años, que nunca antes tuvo planteos al respecto y que, recién ahora, ha introducido la cuestión respecto de un integrante del Consejo afín al Poder Ejecutivo en ejercicio en 2013. Resulta cuanto menos llamativa la oportunidad de la sentencia, mientras se tratan en ese organismo cuestiones como las mencionadas en párrafos anteriores y, además, varias denuncias del Ejecutivo contra jue- ces que dictan fallos que le resultan adversos a su ideología de base.

Tampoco resulta azaroso que uno de los sectores de la justicia más fustigados sea el fuero laboral. En un paradigma que pretende retrotraernos a viejas recetas de flexibilización y privatización como variables de ajuste, como lo evidencia la sanción de la también judicialmente cuestionada ley 27.348 que modifica el sistema de cobertura de riesgos del trabajo; no resulta extraño que los focos de ataque sean tanto jueces laboralistas como abogados que pugnan por la defensa de los derechos 
de los trabajadores, sentido mismo de la aparición del derecho laboral como rama especializada y autónoma. Una república verdaderamente democrática y con justicia social no puede desarrollarse con la obliteración de la defensa judicial de los derechos fundamentales que la Constitución y el ordenamiento jurídico nacional les reconocen a la clase trabajadora.

Con no menor preocupación, seguimos consternados el caso de la dirigente social Milagro Sala que lleva más de 500 días privada ilegalmente de la libertad. Su situación ha motivado las intervenciones del Grupo de Trabajo sobre Detención Arbitraria del Consejo de Derechos Humanos de la ONU y de la Comisión Interamericana de Derechos Humanos (CIDH) en su análisis del caso y reciente visita. En el mismo sentido se han pronunciado la Presidencia del Parlasur y el Secretario General de la Organización de Estados Americanos, Luis Almagro. Por su elocuencia y para no sobreabundar, adscribimos a la cita textual del comunicado de prensa hecho público por la CIDH que en la parte pertinente afirma:

"En su Informe sobre el uso de la prisión preventiva en las Américas, la CIDH reiteró que la presunción de inocencia es la base para la regla general de que "toda persona sometida a proceso penal debe ser juzgada en libertad". La prisión preventiva es excepcional, solo puede extenderse por un período razonable y no puede ser usada como una medida punitiva... la CIDH expresa su preocupación con respecto a la detención preventiva prolongada de Milagro Sala, y llama al Estado argentino, en particular a la provincia de Jujuy, a tomar acciones urgentes para responder las recomendaciones emitidas por el Grupo de Trabajo".

Las ideas-fuerza de estas decisiones políticas están sintetizadas en la propia frase del titular del actual titular PEN: "Los jueces tienen que saber que buscamos la verdad o buscaremos otros jueces que nos representen". La independencia del Poder Judicial es un requisito fundamental para la vigencia del Estado de Derecho, por lo cual apelamos a que cesen las acciones tendientes a contar con un aparato judicial afín al poder político de turno.

Ya en el ámbito propio del quehacer universitario; nos preocupa y adherimos al repudio que hiciera nuestra Universidad respecto de lo sucedido en la Facultad de Ciencias Agrarias de la Universidad Nacional de Jujuy, que culminó con la detención ilegal y arbitraria de los estudiantes y referentes del claustro estudiantil Joaquín Quispe e Ignacio García como resultado del accionar de la fuerza pública, transgrediendo lo establecido en el Artículo 31 de la Ley Nº 24.521 de Educación Superior (v.g.; "... La fuerza pública no puede ingresar en las instituciones universitarias nacionales si no media orden escrita previa y fundada de juez competente o solicitud expresa de la autoridad universitaria legítimamente constituida...”). El operativo policial desplegado contra los estudiantes de aquella unidad académica, a todas luces contraria a derecho, constituye un avasallamiento a la autonomía universitaria.

En igual sentido; alumnos secundarios de una escuela de la localidad bonaerense de Berisso, que recientemente reclamaban mejoras edilicias en la puerta de la Municipalidad, fueron reprimidos por efectivos de la Policía Bonaerense y Local.

Por tales fundamentos, nos sumamos a las adhesiones y muestras de solidaridad señalando la gravedad de lo ocurrido en ambos casos, y reiteramos nuestra preocupación, exigiendo que se sancione a los responsables para que estos hechos no vuelvan a reiterarse.

$\mathrm{Al}$ igual que la intromisión en el Poder Judicial, estos hechos puntuales se enmarcan en el lugar subalterno planificado para la educación pública. Muestras de ello son la falta de voluntad para 
arribar a un acuerdo entre las autoridades nacionales y algunas provinciales y los gremios docentes en cuanto a la actualización de los salarios, depreciados frente a la inflación y demás condiciones laborales. Agrava esta situación la ausencia de diálogo y el incumplimiento de la ley que garantiza las paritarias nacionales docentes. La respuesta de los trabajadores de la educación, en todos sus niveles; ha sido expresada en medidas de fuerzas, movilizaciones, clases públicas y la instalación de una carpa docente itinerante, entre otras.

La Ley 26.075, denominada "Ley de Financiamiento Educativo", fue sancionada el 21 de diciembre de 2005 y promulgada el 9 de enero de 2006. Entre sus objetivos se estableció el “...incremento de la inversión en educación, ciencia y tecnología por parte del Gobierno nacional, los Gobiernos provinciales y el de la Ciudad Autónoma de Buenos Aires, en forma progresiva, hasta alcanzar en el año 2010 una participación del Seis por Ciento en el Producto Bruto Interno...”. En el artículo 10 establece textualmente que el Ministerio de Educación, Ciencia y Tecnología juntamente con el Consejo Federal de Cultura y Educación y las entidades gremiales docentes con representación nacional, acordarán un Convenio Marco que incluirá pautas generales referidas a: a) condiciones laborales, b) calendario educativo, c) salario mínimo docente y d) carrera docente. Posteriormente, en abril de 2007, esta Ley de Financiamiento se reglamenta a través del Decreto N ${ }^{\circ} 457 / 07$ que señala que: "corresponderá que el Convenio Marco trate todas las cuestiones laborales generales que integran la relación de empleo de los trabajadores docentes de las jurisdicciones provinciales y de la Ciudad Autónoma de Buenos Aires. Esto es: Retribución mínima de los trabajadores docentes y materias de indole económica, laboral, asistencial, previsional y, en general, las condiciones de trabajo". Contra legem, el PEN, hasta el día de hoy, no cumplió con su obligación legal, omitiendo hacer el llamado a la Paritaria Nacional Docente. La realidad de los trabajadores de la educación en sus distintos niveles, no escapa a un contexto de crisis social marcada por la retracción del consumo, el aumento de los precios de los artículos de primera necesidad y servicios públicos esenciales, la desocupación y los indicadores de pobreza e indigencia.

Estas acciones/omisiones planificadas, se completan con el ingreso al Parlamento Nacional del llamado "Plan Maestro" remitido por el Poder Ejecutivo Nacional que expresamente prevé que ....dada la organización del sistema educativo argentino, la política salarial docente es definida en el nivel provincial...", entre otras cuestiones que habrán de ser objeto de reflexión, pensamiento crítico y evaluación en un futuro cercano atendiendo a las transformaciones estructurales que propone. En el ámbito local; celebramos que el pasado miércoles 26 de abril se desarrollaron con normalidad las primeras elecciones de delegados gremiales de ADULP en la Facultad de Ciencias Jurídicas y Sociales de la UNLP, resultando electa la lista celeste y blanca. Felicitamos a todos los trabajadores docentes por tan trascendente acto democrático y a los delegados que fueron elegidos en dichos comicios. Esperamos que esta histórica concreción sea el puntapié de un proceso de dignificación de la tarea docente en nuestra unidad académica, empezando por la operativización del Convenio Colectivo de Trabajo vigente.

En igual sentido, tenemos el agrado de poder ingresar al Consejo Editorial Nacional a los profesores Gustavo Ferreyra (Profesor Titular de la materia Derecho Constitucional de la Universidad de Buenos Aires); Juan Stinco (Profesor de Derecho Administrativo de la Universidad de Buenos Aires) y Gustavo Arballo (Profesor de la Facultad de Derecho de la Universidad Nacional de La Pampa). 
Asimismo, nos satisface incorporar al Consejo Editorial UNLP a los docentes Ángel Carballal (Profesor de Derecho Tributario); Rodolfo Sosa (Derecho Laboral) y Ricardo César Andreu (Economía Política).

También les damos la bienvenida al Comité de Redacción Docente a los profesores de nuestra Facultad Guillermo Justo Cháves, Natalia Barriviera y Julián Portela. Y al Comité Editorial de Graduados a las abogadas Florencia Titarelli y Cecilia Villegas. Por último recibimos en el Comité Editorial Estudiantil a Carmela Percow y Nahuel Castro.

Respecto de la organización del equipo de trabajo de ReDeA, incorporamos a los siguientes Editores Temáticos: 1) Derecho Penal: Profesores Paola Catino, Martín Lorat; 2) Derecho Público: Profesor Guillermo Raúl Moreno y Abog. Lucía Villarreal; Derecho Laboral y Previsional: Abogada Zarina Surache; 3) Derecho y Ciencias Sociales: Abogada Daniela Cipolla; 4) Derecho Privado: Profesoras Rosario Echevesti y Lorena Muñoz y 5) Derechos Humanos: Abogado Román Dé Antoni. En el presente número inauguraremos cuatro secciones nuevas; Novedades Legislativas, a cargo del Abog. Eduardo Baldi; Novedades de la Corte Interamericana de Derechos Humanos a cargo del Abog. Mariano Fantoni; Novedades de la Corte Suprema de Justicia de la Nación a cargo del Abog. Juan Francisco Díaz y Novedades de la Suprema Corte de Justicia de la Provincia de Buenos Aires, a cargo del Abog. Francisco Orsini.

Finalmente, agradecer a todos los revisores externos que, solidariamente corrigen en forma anónima, con esmero y dedicación los trabajos sometidos a referato.

A todos ellos, les agradecemos sumarse a trabajar en este proyecto académico, colectivo y heterogéneo.

Con estas líneas de bienvenida a nuestro tercer número, alentamos a nuestros lectores, potenciales autores, a reflexionar sobre estas cuestiones y acercarnos sus aportes.

El volumen de invierno de 2017 los espera. 